\title{
Correction to: Current Methodologies and Implications of Phase Identification of the Vertical Jump: A Systematic Review and Meta-analysis
}

\author{
Alexander Neale Eagles ${ }^{1} \cdot$ Mark Gregory Leigh Sayers $^{1} \cdot$ Matthew Bousson $^{1}$ • \\ Dale Ingham Lovell ${ }^{1}$
}

Published online: 21 November 2017

(c) Springer International Publishing AG 2017

\section{Correction to: Sports Med DOI 10.1007/s40279-015-0350-7}

Pages 1313-5, Table 1, column 1: The cell entries in the 'Reference' column, which previously read:

Cormack et al. [28]

Chiu et al. [29]

Chiu and Salem [30]

Crewther et al. [31]

Floría and Harrison [32]

Johnson and Bahamonde [33]

McLellan et al. [18]

Moir et al. [20]

Moir [34]

Moir et al. [19]

Riggs and Sheppard [35]

Street et al. [25]

Vanrenterghem et al. [36]

Cappa and Behm [37]

The original article can be found online at https://doi.org/10.1007/s40279-015-0350-7.

Alexander Neale Eagles

a.n.eagles23@gmail.com

Mark Gregory Leigh Sayers

MSayers@usc.edu.au

Matthew Bousson

mattbousson@gmail.com

Dale Ingham Lovell

dlovell@usc.edu.au

1 Faculty of Science, Health, Education, and Engineering, University of the Sunshine Coast, Maroochydore, QLD, Australia
Dowling and Vamos [38]

Hatze [39]

Leontijevic et al. [40]

McElveen et al. [41]

Meylan et al. [42]

Meyland et al. [43]

should read:

Cormack et al. [69]

Chiu et al. [36]

Chiu and Salem [37]

Crewther et al. [38]

Floría and Harrison [39]

Johnson and Bahamonde [40]

McLellan et al. [20]

Moir et al. [22]

Moir [41]

Moir et al. [21]

Riggs and Sheppard [42]

Street et al. [32]

Vanrenterghem et al. [43]

Cappa and Behm [44]

Dowling and Vamos [45]

Hatze [46]

Leontijevic et al. [47]

McElveen et al. [48]

Meylan et al. [49]

Meylan et al. [50] 